\title{
LEINAWEAVER, Jessaca B. 2008. The Circulation of Children. Kinship, Adoption, and Morality in Andenean Peru
}

\author{
Marco Julián Martínez-Moreno
}

\section{(2) OpenEdition Journals}

Edição electrónica

URL: http://journals.openedition.org/aa/289

DOI: $10.4000 /$ aa.289

ISSN: 2357-738X

Editora

Programa de Pós-Graduação em Antropologia Social (UnB)

\section{Edição impressa}

Data de publição: 1 julho 2012

Paginação: 213-316

ISSN: 0102-4302

\section{Refêrencia eletrónica}

Marco Julián Martínez-Moreno, «LEINAWEAVER, Jessaca B. 2008. The Circulation of Children. Kinship, Adoption, and Morality in Andenean Peru», Anuário Antropológico [Online], v.37 n. 1 | 2012, posto online no dia 01 outubro 2013, consultado o 28 abril 2021. URL: http://journals.openedition.org/aa/289 ; DOI: https://doi.org/10.4000/aa.289

\section{(c) $)(9)$}

Anuário Antropológico is licensed under a Creative Commons Atribuição-Uso Não-Comercial-Proibição de realização de Obras Derivadas 4.0 International. 


\title{
LEINAWEAVER, Jessaca B. 2008. The Circulation of Children. Kinship, Adoption, and Morality in Andenean Peru. Durham, Londres: Duke University Press. 225 pp
}

\author{
Marco Julián Martínez-Moreno \\ PPGAS, UnB
}

The Circulation of Children. Kinship, Adoption, and Morality in Andenean Peru es una etnografía sobre la creación de lazos de parentesco en relación a discursos internacionales, la construcción de la nación y la agencia de actores indígenas y "blancos" en Ayacucho, Perú.

La autora, Jessaca B. Lainaweaver, Doctora en Antropología por la Universidad de Michigan y actualmente profesora de la Universidad de Brown, inicia su texto con la declaración de abandono y remisión a orfelinatos de niños y niñas. Ella anota que, a pesar de que esos niños fueron cuidados por adultos, para las agencias de Estado, como la policía u organizaciones no gubernamentales a cargo de la promoción de los derechos de los niños, éstos eran incompetentes para garantizar el interés superior del menor. La falta de garantías radicaba en la pobreza en la cual vivían adultos y niños y por la supuesta ausencia de una relación paternal. En efecto, quienes estaban a cargo de aquellos niños y niñas eran abuelos, tíos o padrinos, de ambos sexos. Por razones legales, los niños institucionalizados podían ser adoptados; los futuros padres serían parejas provenientes de países desarrollados, quienes, ante la imposibilidad de concebir naturalmente, buscaban garantizar una vida digna a niños del tercer mundo.

Lainaweaver parte del concepto "circulación de niños/as" (circulation of children), que da cuenta de la movilidad de niños entre los hogares de familiares, las instituciones estatales y las familias adoptivas, además de la formación de relaciones significativas entre niños, progenitores, padrinos, agentes de Estado y representantes de organizaciones no gubernamentales. La autora argumenta, de manera análoga al tráfico de mujeres desarrollado por Gayle Rubin, inspirado en el intercambio de mujeres de Lévi-Strauss, que la circulación de niños permite relaciones de alianza entre unidades familiares a través de la institución del compadrazgo, siendo efectuadas en cualquier momento y ocasión. De este modo, ella diferencia esta forma de flujo del matrimonio, que en términos temporales y ocasionales es restricto. Niños, progenitores y compadres se emparentan a 
través de relaciones de ayuda mutua en la crianza. Ello asegura educación, ascenso social, providencia económica y seguridad a los niños.

Leinaweaver se interesa por cómo las personas conciben sus relaciones de parentesco vinculadas a ideologías globales de reproducción, inscribiéndose así en la inflexión de los estudios de parentesco inaugurada por David Schneider ([1968] 1980) $)^{1}$, donde el parentesco sería más que la proyección sobre el "otro" de categorías euro-americanas como familia, sangre, sexo y biología. La autora se centra en la construcción de la familiaridad y la parentela, en la red de relaciones individuales establecidas a lo largo de la vida en términos de escogencia, reproducción y economía política. Entonces, la circulación de niños es concebida como un proceso activo donde emociones individuales, objetivos familiares y acciones gubernamentales dirigen la formación y transformación del relacionamiento (relatedness) y la sociabilidad.

La etnografía está estructurada en siete capítulos, agrupados en tres partes. Los tres primeros tratan los procesos políticos y económicos que legitiman la figura de la adopción para el establecimiento de relaciones de parentesco a distancia. Los capítulos cuatro al seis abordan el proceso de circulación de niños a nivel local, analizando el compadrazgo y la conformación del sentido de cercanía y familiaridad de los niños inmersos en el flujo. Como conclusión, la autora presenta un ensayo en el que argumenta que la circulación de niños es una forma de reproducción social en el entrecruzamiento de códigos normativos internacionales y un tipo de parentesco local, rastreable e interpretable desde una perspectiva histórica y cultural, el cual los agentes de Estado deslegitiman desde una posición moral que privilegia una visión burguesa de concebir la familia y la infancia.

¿Cómo entender la lógica cultural mediante la cual se establecen las relaciones familiares en Ayacucho? Leinaweaver resalta que, en su estudio, el "parentesco" se encuentra en tensión, pues es al tiempo un concepto teórico como un concepto de uso social. Para ella, el sentido ayacuchano de relatedness, al tiempo heredado y creado, es una noción local significativa y una categoría analítica, una relación verdadera y cuestionada moralmente.

La autora presenta una breve introducción a los estudios sobre el parentesco en los Andes, rastreando la circulación de niños en la historia y resaltando la lógica inca de establecimiento de alianzas con las comunidades incorporadas al imperio, donde el ayllu daba cuenta de la circulación de niños al tiempo que eran objeto de cuidado colectivo. Luego, recuenta el periodo colonial, cuando la invasión español a configuró la emergencia de una nueva categoría de sujetos, los mestizos, también llamados huérfanos, al ubicarse en un espacio liminal entre 
la producción de parentesco local e ibérico. Simultáneamente, describe ella, se fue estructurando la jerarquía socio racial de la sociedad colonial, base de la futura república: los atributos fenotípicos indígenas se equipararon a pobreza y sus costumbres a expresiones salvajes.

Los indígenas, convertidos en campesinos por el Estado peruano a mediados del siglo XX, quedaron en la base social, donde las relaciones sociales y raciales determinaban el estatus de los colectivos e individuos. El resultado fue la exclusión y subordinación indígena a un ideal de sociedad europea, blanca, cuyo centro era, y sigue siendo, la ciudad de Lima. La autora menciona que bajo estos supuestos ideológicos, el movimiento hacia un blanqueamiento, y de lo rural a lo urbano, es significativo en la relación de compadrazgo, donde los progenitores, ubicados en la periferia, buscan que sus hijos vayan hacia el centro. El objetivo familiar es que sus hijos consigan superarse, disfrutando de los beneficios de la sociedad urbana.

Leinaweaver puso especial atención a las últimas dos décadas del siglo XX, cuando la región de Ayacucho estuvo inmersa en un conflicto armado entre guerrillas izquierdistas y el gobierno nacional. El enfrentamiento provocó matanzas, desaparecimientos y desplazamientos forzados, desestructurando las comunidades locales. Resultado del conflicto fue un grupo significativo de niños huérfanos, por lo cual, la acción social y humanitaria justificaron la construcción de orfelinatos. Se configuró la institucionalidad que relacionó instancias de cuidado local con entidades internacionales de derecho. Esto permitió instaurar el ideal de familia nuclear en Ayacucho y ejercer prácticas de eugenesia y puericultura para mejorar el cuerpo de la nación.

Ya en su presente etnográfico, Leinaweaver narra cómo niños son enviados donde sus padrinos con la función de acompañar al adulto, generalmente una mujer, lo que implica colaborar en las labores domésticas y adquirir habilidades sociales para la vida adulta. Aquí la autora distingue entre ayudar para las niñas y trabajar para los niños, resaltando la construcción de diferencias de género, entre otras presentes en el libro. Sin embargo, resalto que la etnografía tiene una perspectiva de relatedness de niñas y mujeres; la percepción de niños y hombres fue poco explorada.

Entre tanto, los niños se acostumbraban al nuevo contexto, construyendo sus relaciones en la medida que el adulto brinda afecto y soporte. Para el niño, estar en el nuevo hogar implica asumir una nueva vida e identidad con la esperanza de que la vida mejore. Así, niños y niñas buscan superarse, categoría que encierra nociones cristianas sobre la redención, ideas desarrollistas sobre la evolución del individuo y nociones ideológicas de la sociedad nacional sobre el blanqueamiento. 
Respecto a la producción de parentesco inscrita en la economía y política global, Leinaweaver encuadra la discusión en la producción de discursos internacionales que legitiman el Estado de derecho como un sistema político universal y benéfico. Resalta que la normatividad que regula la existencia de la infancia tiene como ancla suposiciones norteamericanas que asumen al sujeto infantil como futuro dirigente de la sociedad, al cual debe garantizarse un correcto y adecuado desarrollo en un hogar con amor y afecto.

Desde esta perspectiva, el Estado peruano legitima la intervención penal en arreglos familiares locales, justifica la declaratoria de abandono a un menor bajo el argumento de protección del “interés superior" del menor (de dieciocho años) y permite el proceso de adopción, inscrito en relaciones económicas y políticas globales donde niños del tercer mundo son trasladados a Europa o los Estados Unidos. En estos países del norte global, los futuros padres deben demostrar que otorgarán al futuro miembro del hogar las posibilidades para su desarrollo psicológico, físico y social en familia.

Finalizando, en la etnografía, las adopciones son descritas en oposición a formas locales de relacionamiento en términos de afecto, resistencia y responsabilidad. Leinaweaver encuentra dos sistemas definiendo la existencia de niños en los orfelinatos. Por un lado, el que define a los niños en relación a su autonomía, ligados a un orden de derecho que los asume como sujetos en constante riesgo. Por otro lado, un sistema de circulación de los niños entre las familiares consolida el tejido social y permite su reproducción como estrategia anclada en la cultura. Así, diferentes nociones sobre el parentesco son contrapuestos, mostrando al universalismo de los derechos como una perspectiva con poder que desconoce y anula contenidos "culturalmente" definidos.

\section{Notas}

1. American Kinship: A Cultural Account. Chicago: University of Chicago Press. 